SUBJECT AREAS:

PROCESS CHEMISTRY

SOLID-STATE CHEMISTRY

Received

21 October 2013

Accepted

5 December 2013

Published

22 January 2014

Correspondence and requests for materials should be addressed to

C.L.R. (colin.raston@ flinders.edu.au)

\title{
Spinning up the polymorphs of calcium carbonate
}

\author{
Ramiz A. Boulos ${ }^{1}$, Fei Zhang ${ }^{1,2}$, Edwin S. Tjandra ${ }^{3}$, Adam D. Martin ${ }^{4}$, Dino Spagnoli ${ }^{3}$ \& Colin L. Raston ${ }^{1}$
}

${ }^{1}$ Centre for NanoScale Science and Technology, School of Chemical and Physical Sciences, Flinders University, Bedford Park, SA 5042 Australia, ${ }^{2}$ Department of Polymer Science and Engineering, School of Chemistry and Chemical Engineering, Shanghai Jiao Tong University, Shanghai 200240, China, ${ }^{3}$ School of Chemistry and Biochemistry, The University of Western Australia, 35 Stirling Hwy, Crawley, WA 6009, Australia, ${ }^{4}$ Department of Chemistry, The University of New South Wales, High St, Kensington, NSW 2052.

Controlling the growth of the polymorphs of calcium carbonate is important in understanding the changing environmental conditions in the oceans. Aragonite is the main polymorph in the inner shells of marine organisms, and can be readily converted to calcite, which is the most stable polymorph of calcium carbonate. Both of these polymorphs are significantly more stable than vaterite, which is the other naturally occurring polymorph of calcium carbonate, and this is reflected in its limited distribution in nature. We have investigated the effect of high shear forces on the phase behaviour of calcium carbonate using a vortex fluidic device (VFD), with experimental parameters varied to explore calcium carbonate mineralisation. Variation of tilt angle, rotation speed and temperature allow for control over the size, shape and phase of the resulting calcium carbonate.

\footnotetext{
arbon dioxide fixation from the atmosphere by marine organisms as large deposits of calcium carbonate is important in the carbon cycle. The rising concentration of carbon dioxide in the atmosphere, estimated to be $40 \%$ higher than preindustrial levels and higher than at any point in the last 800,000 years ${ }^{1}$, has led to a shift in the equilibrium of dissolved $\mathrm{CO}_{2}$ in seawater. This has lowered the $\mathrm{pH}$ of seawater and along with increasing temperatures, has greatly affected the optimum conditions for calcium carbonate $\left(\mathrm{CaCO}_{3}\right)$ mineralisation ${ }^{2,3}$. Deposition of $\mathrm{CaCO}_{3}$ by marine organisms, in the form of aragonite in the nacreous layer or inner shell $^{4-6}$, is therefore likely to be tested by the climate change ${ }^{7,8}$ in the Anthrapocene era ${ }^{9}$. Controlling the formation of $\mathrm{CaCO}_{3}$ polymorphs is important in understanding the mineralisation process with such changing environmental conditions, and for this purpose we used the recently developed, continuous flow processing, vortex fluidic device (VFD $)^{10-13}$. While the conditions here are much more extreme and different to those likely to be encountered in the environment in the future, the results highlight the conditions required for selective preparation of different polymorphs of calcium carbonate. The vortex fluidic device (VFD), is capable of producing thin films in which high shear forces provide a mechanical energy which is effective in manipulating the growth of a range of diverse materials, including the synthesis of mesoporous silica ${ }^{11}$, decorating carbon nano-onions with palladium nanoparticles ${ }^{12}$, exfoliation of laminar material ${ }^{10}$, forming composite material with live algal cells and controlling organic reactions ${ }^{13}$.

Calcite is the most stable polymorph of $\mathrm{CaCO}_{3}$ and is the least soluble in water as opposed to vaterite, which is the least stable polymorph and most soluble in water. These stability differences arise from the way the calcium and carbonate ions are assembled in the extended solid-state structures, Fig. $1 \mathrm{a}^{14-17}$. Aragonite and calcite have similar structures with the inter-planar carbonate ions in a staggered arrangement relative to each other, minimising electrostatic repulsion, while in the less dense vaterite they are almost eclipsed relative to each other. The structures have been further explored in the present study using the recently developed Hirshfeld surface analysis ${ }^{18}$, in gaining further insight into the interplay of the ions in the solid state. Transformation from vaterite to aragonite and calcite is possible at $0-30^{\circ} \mathrm{C}$ and $60-80^{\circ} \mathrm{C}$ respectively ${ }^{19,20}$. In addition, aragonite is readily converted to calcite in nature at temperatures higher than $380^{\circ} \mathrm{C}^{21}$. The nucleation and growth of the three different polymorphs can be manipulated through the addition of crystal modifiers, including bio-polymers, inorganic salts, and macromolecules ${ }^{22,23}$. Developing protocols for gaining access to the different polymorphs of calcium carbonate is central to mimicking processes in nature, for example in generating synthetic aragonite, which has only recently been developed using polymer-mediated mineral growth, in addition to layer-by-layer deposition of a porous organic material ${ }^{24}$. Also important is gaining control over the interconversion of the different polymorphs of calcium carbonate where particular applications demand the presence of one phase of
} 


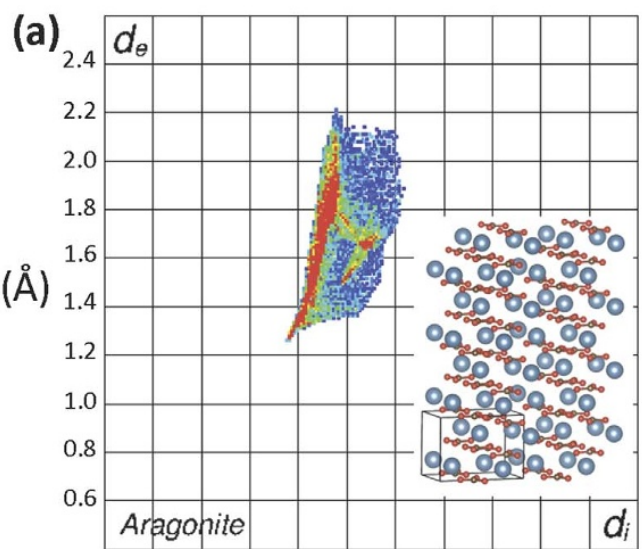

$\begin{array}{llllllllll}0.6 & 0.8 & 1.0 & 1.2 & 1.4 & 1.6 & 1.8 & 2.0 & 2.2 & 2.4\end{array}$

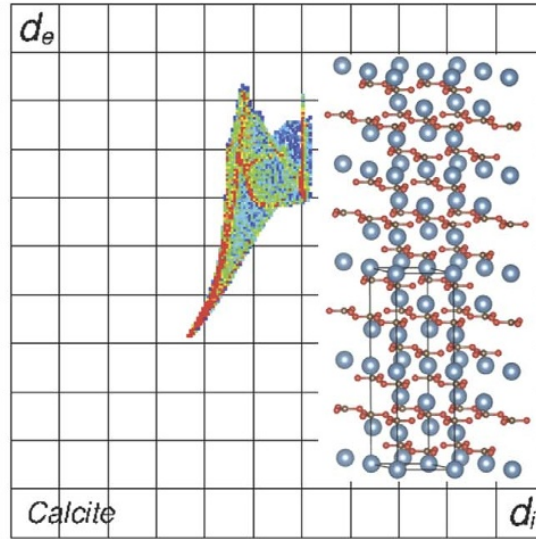

$\begin{array}{llllllllll}0.6 & 0.8 & 1.0 & 1.2 & 1.4 & 1.6 & 1.8 & 2.0 & 2.2 & 2.4\end{array}$

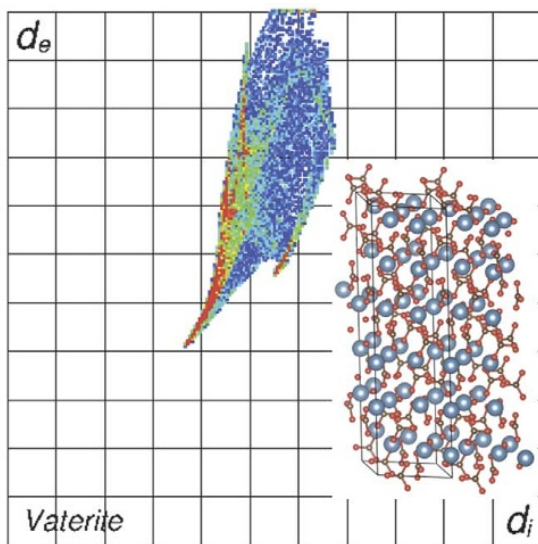

$\begin{array}{llllllllll}0.6 & 0.8 & 1.0 & 1.2 & 1.4 & 1.6 & 1.8 & 2.0 & 2.2 & 2.4\end{array}$

(Å)

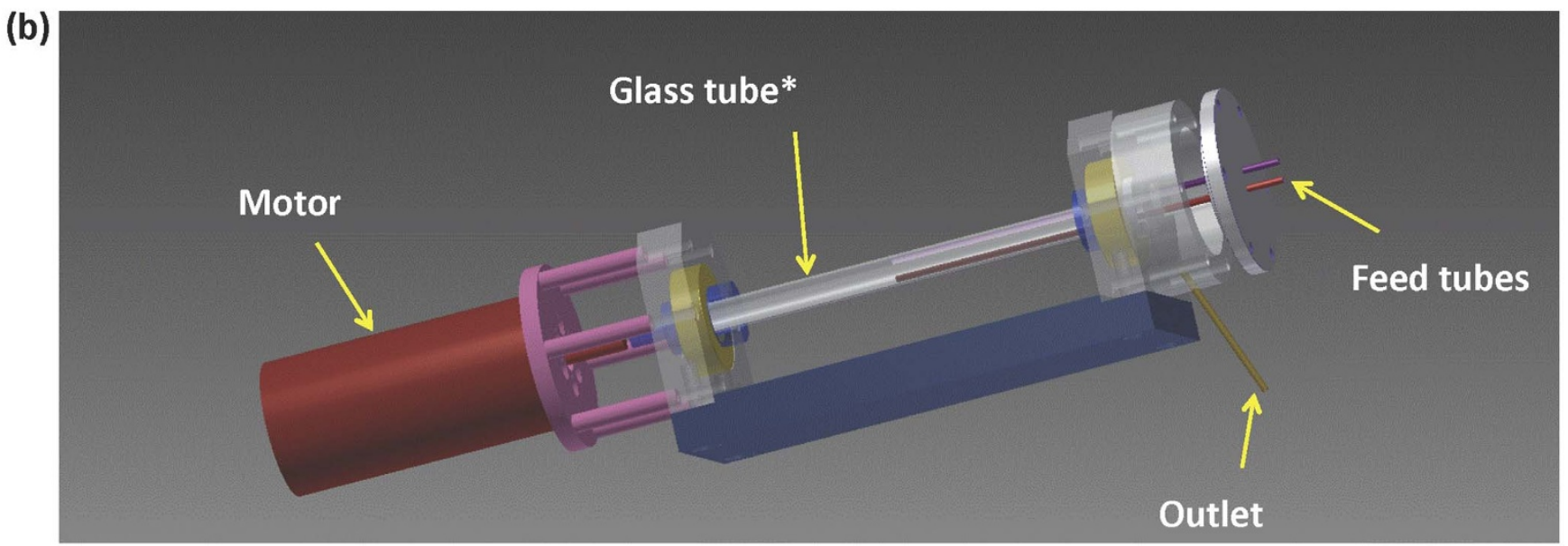

Figure 1 (a) Hirshfeld surfaces of the calcium carbonate polymorphs, and (b) schematic of the vortex fluidic device (VFD). *Standard 10 mm NMR tube. 1(b) reproduced with permission from Bob Northeast.

specific particle size and morphology (e.g. paper coating) ${ }^{25}$ while another application may require the in situ conversion of $\mathrm{CaCO}_{3}$ from one phase to another, such as in drug delivery ${ }^{26}$.

\section{Results}

The VFD used herein has a $10 \mathrm{~mm}$ tube with the capacity for high rotational speeds and variation in the tilt angle, $\theta$, relative to the horizontal position, Fig. 1b. The latter can dramatically affect the shear forces present within the dynamic thin films ${ }^{13}$, which include solutions of Milli-Q water, seawater, and a mixture of ethanol and Milli-Q water, noting that ethanol is effective in $\mathrm{CaCO}_{3}$ polymorph control under conventional batch processing ${ }^{27}$. Milli-Q water spiked with $\mathrm{NaCl}$ matching the activity of salt in seawater and Milli-Q water spiked with $1 \%$ and $2 \%$ of $\mathrm{Mg}^{2+}$ also features in the study, noting that the presence of $\mathrm{Mg}^{2+}$ ions attenuates the growth of calcite with no effect on aragonite formation ${ }^{28,29}$. Aqueous solutions of $\mathrm{NaHCO}_{3}$ as the source of carbonate ions and aqueous solutions of $\mathrm{CaCl}_{2}$ as the source of calcium ions were fed into the VFD at a flow rate of $1 \mathrm{~mL} /$ min, in parallel with classical batch processing in a round bottom flask as control experiments. The effect of varying the ratios of $\mathrm{HCO}_{3}{ }^{-}: \mathrm{Ca}^{2+}$ on $\mathrm{CaCO}_{3}$ polymorph formation was investigated with relevance to the changing atmospheric and seawater concentration of $\mathrm{CO}_{2}$ (see experimental).

For batch processing at room temperature, $71 \%$ of the samples produced calcite quantitatively, as established using $\mathrm{X}$-ray diffraction (XRD) data, Fig. 2a. A 2:1 ratio of $\mathrm{HCO}_{3}{ }^{-}$and $\mathrm{Ca}^{2+}$ results in a mixture of calcite (66.8\%) and vaterite (33.2\%), and decreasing or increasing the ratio of $\mathrm{HCO}_{3}{ }^{-}: \mathrm{Ca}^{2+}$ increased the percentage of calcite in the product at the expense of forming vaterite. For batch processing at $80^{\circ} \mathrm{C}$ there was little control in the formation of the $\mathrm{CaCO}_{3}$ polymorphs, with XRD data revealing a mixture of aragonite, calcite and vaterite in all but one sample. Nevertheless, as the ratio of $\mathrm{HCO}_{3}{ }^{-}$to $\mathrm{Ca}^{2+}$ increases, the percentage of vaterite increases and to a lesser extent the percentage of aragonite increases, whereas the percentage of calcite decreases, Fig. 2 a.

At room temperature, operating the VFD at $500 \mathrm{rpm}$ at a tilt angle of $45^{\circ}$ afforded a mixture of calcite and vaterite in $57 \%$ of the samples, while at $80^{\circ} \mathrm{C}$ the percentage of samples with both polymorphs dropped to $29 \%$, Fig. 2 b. Operating the VFD at $4500 \mathrm{rpm}$ at a tilt angle of $45^{\circ}$ gave no difference in the outcome for the continuous flow processing at room temperature and $80^{\circ} \mathrm{C}$, with calcite being exclusively formed. The choice of $45^{\circ}$ tilt relates to the angle that provides the greatest shear below $60^{\circ}$ tilt. This has been judged by extensive optimisation of exfoliation of graphene and simple Diels Alder reactions ${ }^{13}$. Vaterite formation at $80^{\circ} \mathrm{C}$ was favoured at $1: 10$ and $10: 1$ ratios of $\mathrm{HCO}_{3}{ }^{-}$to $\mathrm{Ca}^{2+}$. Reducing the angle of rotation of the VFD from $45^{\circ}$ to $0^{\circ}$ at $500 \mathrm{rpm}$ also selectively afforded pure calcite for all ratios, irrespective of the temperature of the reaction.

We have shown that the VFD is effective in forming calcite or vaterite at high or low shear in aqueous systems with no evidence of the formation of aragonite despite its presence in nature in molluscan shells. Substituting Milli-Q water for seawater in the VFD and also in batch processing afforded vaterite quantitatively, Fig. 2c. Optimum conditions for obtaining vaterite in the VFD are low shear 
(a)
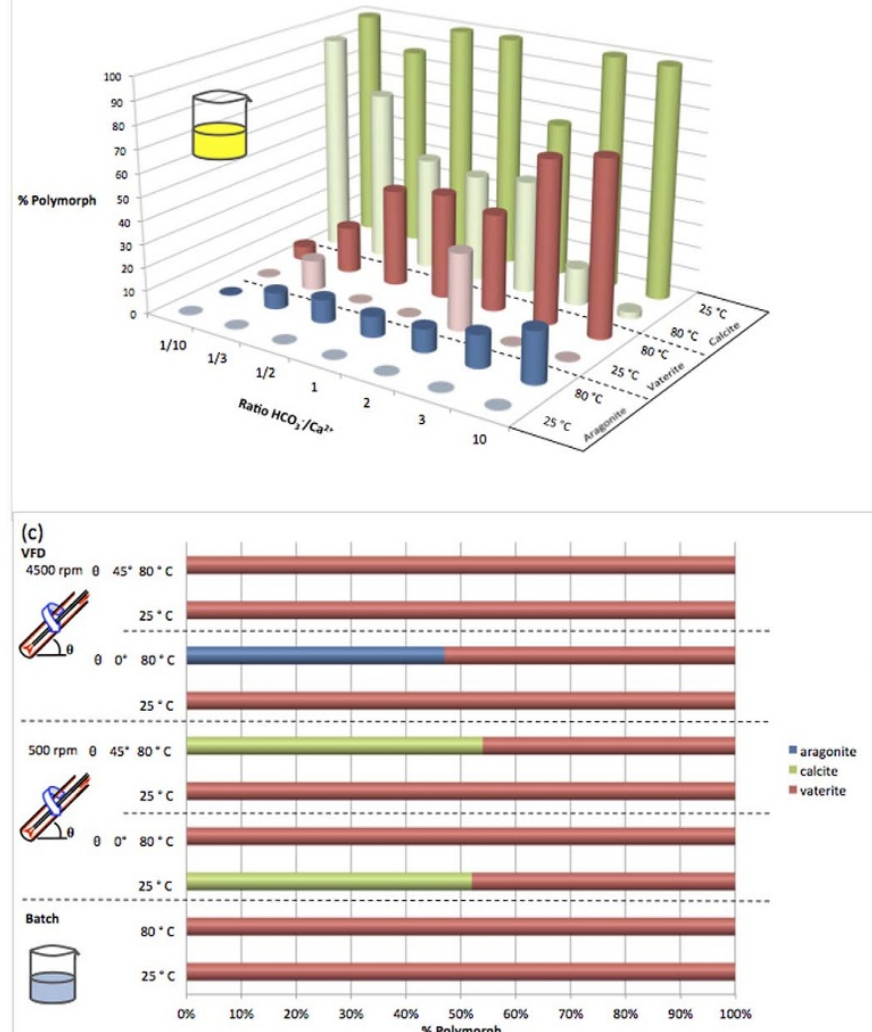

(b)

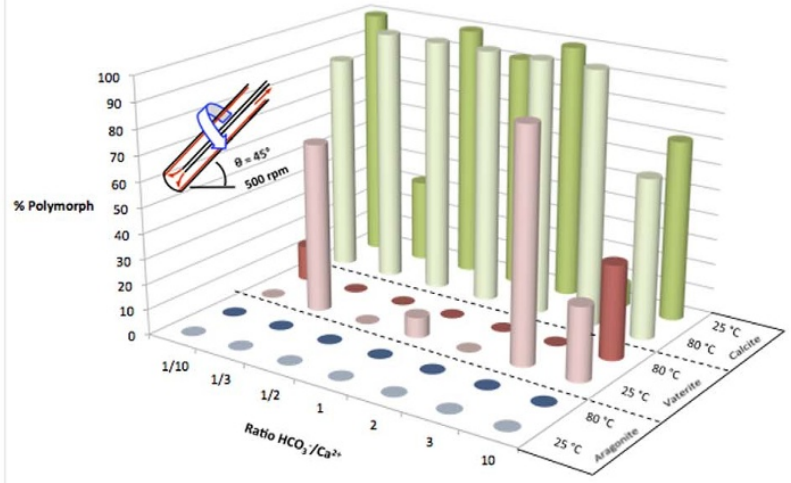

(d)

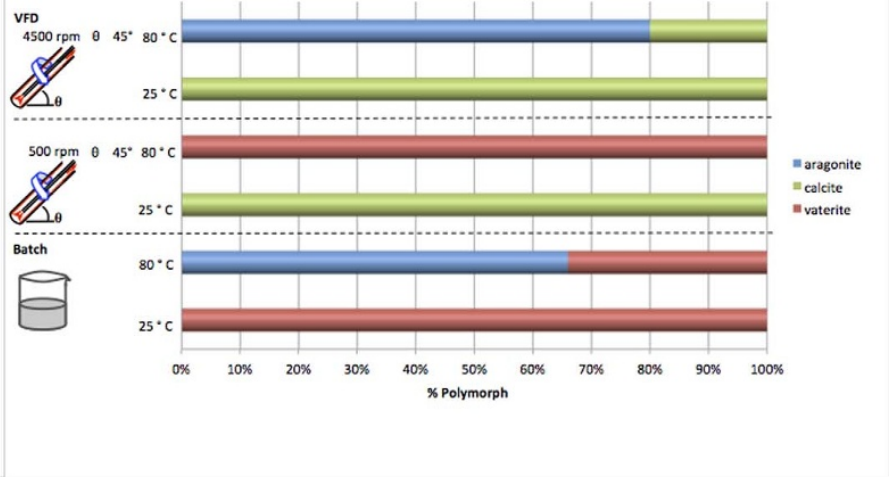

Figure $2 \mid$ Effect of $\mathrm{HCO}_{3}{ }^{-} / \mathrm{Ca}^{2+}$ ratio, shear, and medium on polymorph synthesis. 3D plots for the ratio of $\mathrm{HCO}_{3}{ }^{-} / \mathrm{Ca}^{2+}$ at room temperature and $80^{\circ} \mathrm{C}$ for (a) batch processing and (b) VFD processing at $500 \mathrm{rpm}, \theta=45^{\circ}$, against percent of the polymorph. $2 \mathrm{D}_{\text {plots for }} \mathrm{CaCO}_{3}$ polymorphs produced in seawater (c) and in $20 \%$ ethanol with Milli-Q water (d). VFD synthesis of $\mathrm{CaCO}_{3}$ at $4500 \mathrm{rpm}$, and $500 \mathrm{rpm}$ at a tilt angle of $\theta=0^{\circ}$, affording calcite exclusively. (VFD jet feed flow rates $1.0 \mathrm{~mL} / \mathrm{min}$ ). For clarity reasons, the order of temperature for calcite in (a) and (b) has been reversed.

at $45^{\circ}$ tilt angle $(500 \mathrm{rpm})$, high shear at $45^{\circ}$ tilt angle $(4500 \mathrm{rpm})$ or $0^{\circ}$ tilt angle, all at room temperature. Aragonite was produced in $45 \%$ yield at $80^{\circ} \mathrm{C}$ using the VFD at a rotation speed of $4500 \mathrm{rpm}$ and $0^{\circ}$ tilt angle. These results may reflect the presence of $\mathrm{Mg}^{2+}$ ions present in seawater inducing the formation of aragonite ${ }^{30}$. This was corroborated by XRD data for material prepared in the presence of $\mathrm{Mg}^{2+}$ ions, with $1 \%$ and $2 \% \mathrm{Mg}^{2+}$ in Milli-Q water which resulted in $1 \%$ aragonite ( $99 \%$ calcite) in the VFD at operating at $500 \mathrm{rpm}$ and $5000 \mathrm{rpm}$, at $45^{\circ}$ tilt at room temperature. For the same conditions in the absence of added $\mathrm{Mg}^{2+}$, the product was exclusively calcite, and batch processing in the presence of $1 \%$ and $2 \% \mathrm{Mg}^{2+}$ resulted in $1 \%$ aragonite $(99 \%$ calcite) and $10 \%$ aragonite $(90 \%$ calcite) respectively, in contrast to forming vaterite and calcite in the absence of $\mathrm{Mg}^{2+}$. The presence of carbonate and calcium ions in seawater made it inherently difficult to measure the concentration of the prepared $\mathrm{NaHCO}_{3}$ and $\mathrm{CaCl}_{2}$ solutions. Rather saturated solutions were prepared by the addition of excess $\mathrm{CaCl}_{2}$ and $\mathrm{NaHCO}_{3}$ to seawater followed by filtration. ICPAES established that the seawater had $12500 \mathrm{ppm} \mathrm{Na}, 1237 \mathrm{ppm} \mathrm{Mg}$, 891 ppm S, 389 ppm K, 400 ppm Ca, 8.9 ppm Sr and 1.35 ppm Si. (The $\mathrm{Na}$ and $\mathrm{Si}$ concentrations are higher than the global mean concentration in seawater of $10561 \mathrm{ppm}$ and $0.03 \mathrm{ppm}$ respectively, while that of $\mathrm{Sr}$ is lower than the average at $13 \mathrm{ppm}$.) Matching the activity of salt in seawater had no effect on aragonite formation with both batch and VFD processing resulting in $100 \%$ calcite.

Addition of ethanol induces aragonite formation ${ }^{27}$ and in the present study the effect of the presence of ethanol was studied for a $20 \%$ volume mixture of ethanol in Milli-Q water, using the VFD and also in batch mode as a control. For a stoichiometric ratio of $\mathrm{HCO}_{3}{ }^{-}$to $\mathrm{Ca}^{2+}$ at $2: 1$, at room temperature, the VFD resulted in the formation of calcite regardless of the speed and tilt angle, Fig. $2 \mathrm{~d}$. In contrast, using the batch mode at room temperature, pure vaterite was obtained, while at $80^{\circ} \mathrm{C}$ a mixture of $64 \%$ aragonite and $34 \%$ calcite resulted. At higher temperatures and low shear stress using the VFD, vaterite was the exclusive product, while at a higher shear stress a mixture of aragonite and vaterite resulted. This is consistent with ethanol stabilising vaterite at higher temperatures by inhibiting its dissolution. Interestingly placing vaterite powder, which was prepared using the VFD operating in continuous flow mode, in water devoid of ethanol and now operating the VFD in the confined mode at a tilt angle of $45^{\circ}$ and room temperature resulted in vaterite to calcite conversion. (The confined mode is for a finite volume of liquid processed in the VFD, where there can be intense shear at high speed in the absence of the viscous drag shear associated with continuous flow operation of the device ${ }^{13}$.) Replacing the water with hexane in the VFD operating under confined mode gave no such phase change and this is consistent with the phase change in Milli-Q water arising from the dissolution of vaterite and the precipitation of the calcium carbonate as calcite.

The effect of tilt angle and speed on calcium carbonate synthesis in the VFD was studied for the ethanol/water system where reactant concentrations can be predetermined unlike in seawater, and where all three polymorphs can be produced, Fig. $2 \mathrm{~d}$. The effect of tilt angles at $4500 \mathrm{rpm}$ and $80^{\circ} \mathrm{C}$ on the percentage of polymorph shows that for tilt angles below $45^{\circ}$, vaterite and aragonite dominate while at $>$ $45^{\circ}$, calcite and aragonite dominate, Fig. 3b. Optimal conditions for aragonite synthesis occur at $45^{\circ}$ with a yield of $80 \%$. A plot of percentage of polymorph versus rotational speed at a tilt angle of $45^{\circ}$ established that at $500 \mathrm{rpm}$ vaterite is exclusively formed, and as the speed increases, the percentage of vaterite decreases to $0 \%$ at just under $4000 \mathrm{rpm}$, Fig. 3c. At $6000 \mathrm{rpm}$, aragonite and calcite are 
present in $80 \%$ and $20 \%$ respectively, a polymorph mixture that is not uncommon in molluscan shells ${ }^{31}$. Above $6000 \mathrm{rpm}$ the percentage of aragonite decreases and that of calcite increases.

Hirshfeld surface analysis, as a recently developed tool for understanding the interplay of molecules and ions in the solid state ${ }^{18}$, highlights differences in the three polymorphs of $\mathrm{CaCO}_{3}$. This includes a variation in the percentage of $\mathrm{O} \cdots \mathrm{Ca}$ and $\mathrm{O} \cdots \mathrm{O}$ interactions in the Hirshfeld surfaces, at 63.8 and $20.4 \%, 63.9$ and $25 \%$, and 53.7 and $34.8 \%$, respectively for vaterite, calcite and aragonite, Fig. $1 \mathrm{a}^{18} \cdot \mathrm{C} \cdots \mathrm{C}$ interactions are absent in the Hirshfeld surfaces of vaterite and calcite, whereas there is a small component in that of aragonite (5.4\%). More significantly, vaterite is distinctly different in having a significant component of $\mathrm{C} \cdots \mathrm{O}$ interactions between carbonate ions, making up $9.1 \%$ of the Hirshfeld surface for the polymorph, which appears as a spike in the bottom right hand side of the fingerprint plot ${ }^{18}$, Fig. 1a.

As well as controlling the polymorphs of $\mathrm{CaCO}_{3}$, the use of the VFD is also effective in controlling the size and morphology of the

(a)

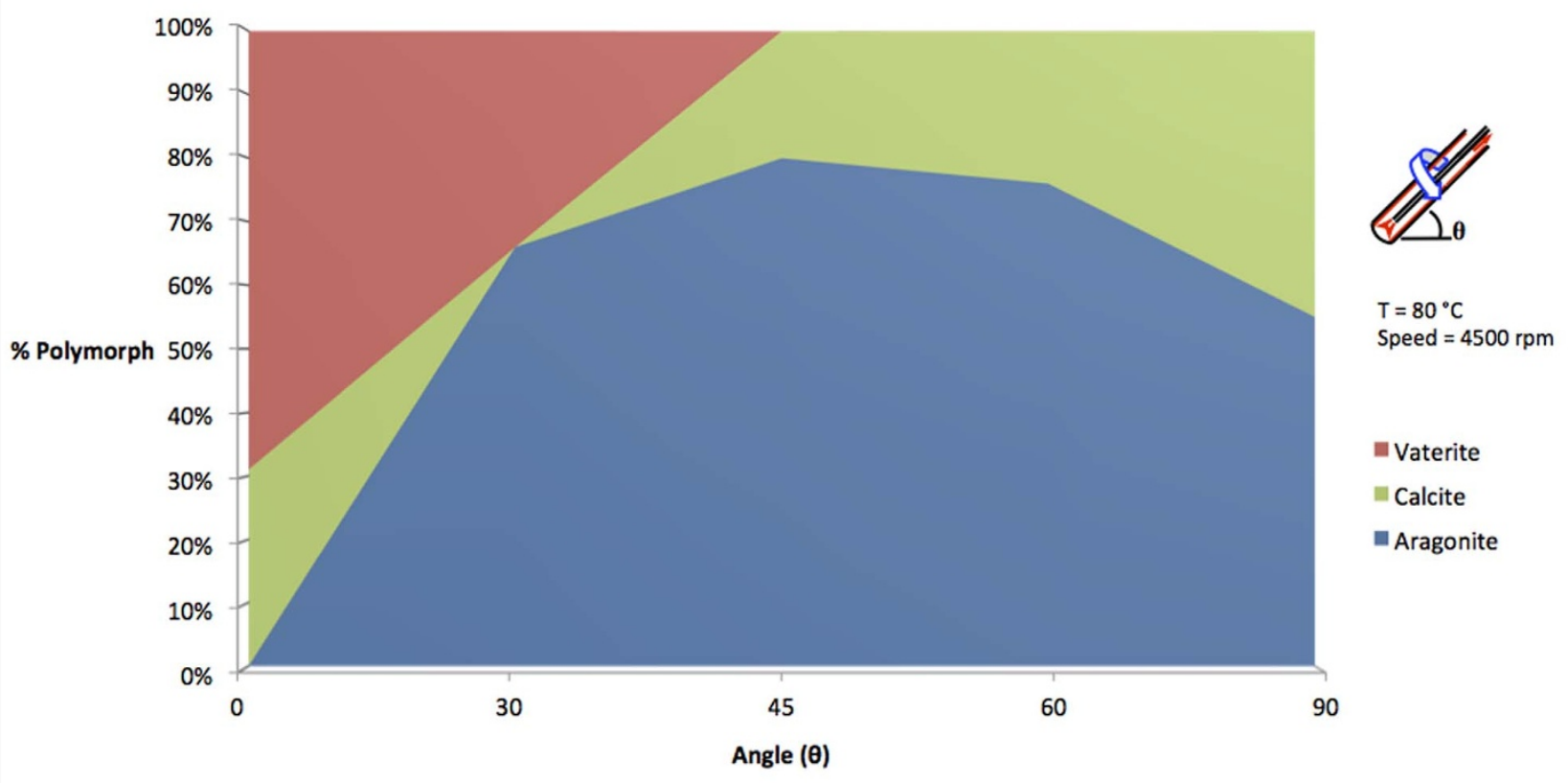

(b)

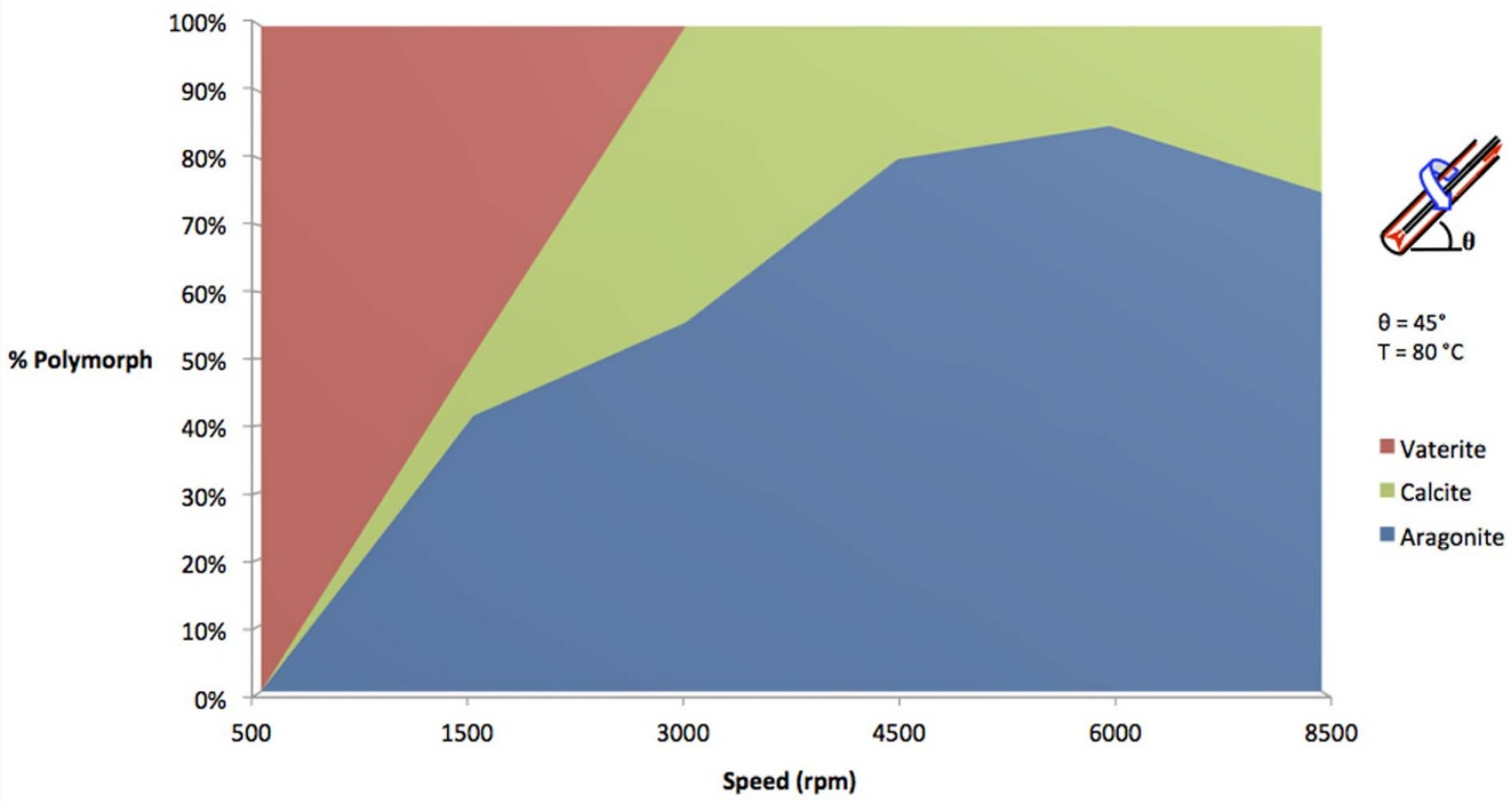

Figure 3 Rotational speed and tilt angle control on calcium carbonate polymorph formation. Varying the tilt angle (a) and speed (b) in $20 \%$ ethanol under continuous flow conditions, for flow rates of $1.0 \mathrm{~mL} / \mathrm{min}$. 
particles. A comparison between the morphology using TEM and SEM for samples processed at $45^{\circ}$ tilt angle and room temperature using the VFD establishes the ability to also control the shape and size of the calcite crystals, with an average size of approximately $1 \mu \mathrm{m}$, Fig. 4a-h. This is in contrast to little control in shape and size for calcite crystals produced using batch processing, Fig. 4i-p.

\section{Discussion}

The results establish that at high temperature and high shear (4500 rpm) in Milli-Q water in the VFD results in the selective formation of the most stable polymorph, namely calcite. In contrast, operating the VFD at room temperature and low shear (500 rpm) favours exclusively vaterite, and this is consistent with previous experiments where $\mathrm{CaCO}_{3}$ produced in a spinning disc processor (SDP) at $500 \mathrm{rpm}$ consists of the vaterite polymorph ${ }^{32}$. (The SDP relates to the VFD in providing a dynamic thin film, but on a disc rather than in a tube.) The high shear forces in the VFD resulting in the formation of calcite are akin to the mechanical energy associated with milling which is capable of inducing a vaterite to calcite transformation ${ }^{33}$.

Replacing the Milli-Q water with seawater in the VFD, however, results in the quantitative formation of vaterite at high shear (4500 rpm), at room temperature and $80^{\circ} \mathrm{C}$. Presumably this arises from the high ionic activity of metal ions and carbonate ions in seawater preferentially precipitating $\mathrm{CaCO}_{3}$ and circumventing the dissolution of vaterite, Eq. 1.

$$
\mathrm{CaCO}_{3(\mathrm{~s})} \rightleftharpoons \mathrm{Ca}_{(\mathrm{aq})}^{2+}+\mathrm{CO}_{3}^{2-}{ }_{(\mathrm{aq})}
$$

The ability to generate a mixture of aragonite and calcite at high shear (4500 rpm) and in $20 \%$ ethanol in the VFD, highlights the delicate balance between the these polymorphs, which is consistent with a relatively small energy difference between their formation energies $^{34,35}$. This relates to similar crystal structures, which are distinctly different to that of vaterite, and this is further highlighted in the Hirshfeld surface analysis.
We have demonstrated the differential formation of crystalline $\mathrm{CaCO}_{3}$ polymorphs under shear using a vortex fluidic device (VFD), unlike in batch processing. The ratio of $\mathrm{Ca}^{2+}$ to $\mathrm{HCO}_{3}{ }^{-}$is important in controlling the polymorph(s) using batch processing while using the VFD, calcite is obtained selectively at high shear, regardless of the tilt angle and temperature. Selective formation of vaterite using seawater under batch conditions occurs at room temperature and $80^{\circ} \mathrm{C}$, and in the VFD at $45^{\circ}$ and high shear. In the VFD up to $45 \%$ aragonite is accessible in seawater and up to $80 \%$ (and $20 \%$ calcite) in a mixture of ethanol and water, which is similar to the ratio of the polymorph in molluscan shells. Overall, the variation in shear and temperature in controlling the polymorphs of calcium carbonate has implications in understanding how marine organisms create their shells as conditions in the oceans change. The ability to control the size, shape and morphology of polymorphs of calcium carbonate is also significant, for a range of applications, from paper coatings to catalysis, to drug delivery, to templates for carbonaceous materials. Moreover, such control establishes a precedent for using the device to control the crystallisation outcome of a raft of materials.

\section{Methods}

The VFD consists of a $10 \mathrm{~mm}$ NMR tube as the reaction chamber with reactants fed into the chamber with controlled flow rates using a peristaltic pump, Fig. 1b. The tilt angle of the VFD can be varied from $0^{\circ}$ to $90^{\circ}$ and the rotational speed can be varied from $500 \mathrm{rpm}$ to $7000 \mathrm{rpm}$. A heat jacket equipped with a heat gun can be used to operate reactions above room temperature.

The $\mathrm{CaCO}_{3}$ was prepared by the reaction of sodium hydrogen carbonate

$\left(\mathrm{NaHCO}_{3}\right)$ and calcium chloride $\left(\mathrm{CaCl}_{2}\right)$ to give calcium hydrogen carbonate (Eq. 2 ) which then decomposes to $\mathrm{CaCO}_{3}, \mathrm{H}_{2} \mathrm{O}$ and $\mathrm{CO}_{2}$ (Eq. 3). $\mathrm{NaHCO}_{3}$ was purchased from Optigen Scientific Pty. Ltd. and was of Optigrade ${ }^{\mathrm{TM}}$, and $\mathrm{CaCl}_{2}$ was purchased from Chem-Supply Pty. Ltd. and was of laboratory reagent quality.

$$
2 \mathrm{HCO}_{3(\mathrm{aq})}^{-}+\mathrm{Ca}^{2+}{ }_{(\mathrm{aq})} \longrightarrow \mathrm{Ca}\left(\mathrm{HCO}_{3}\right)_{2(\mathrm{aq})}
$$

$$
\mathrm{Ca}\left(\mathrm{HCO}_{3}\right)_{2} \longrightarrow \mathrm{CaCO}_{3(\mathrm{~s})}+\mathrm{H}_{2} \mathrm{O}_{(\mathrm{l})}+\mathrm{CO}_{2}(\mathrm{~g})
$$

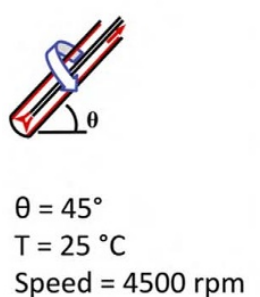

Speed $=4500 \mathrm{rpm}$

$$
\text { ( }
$$
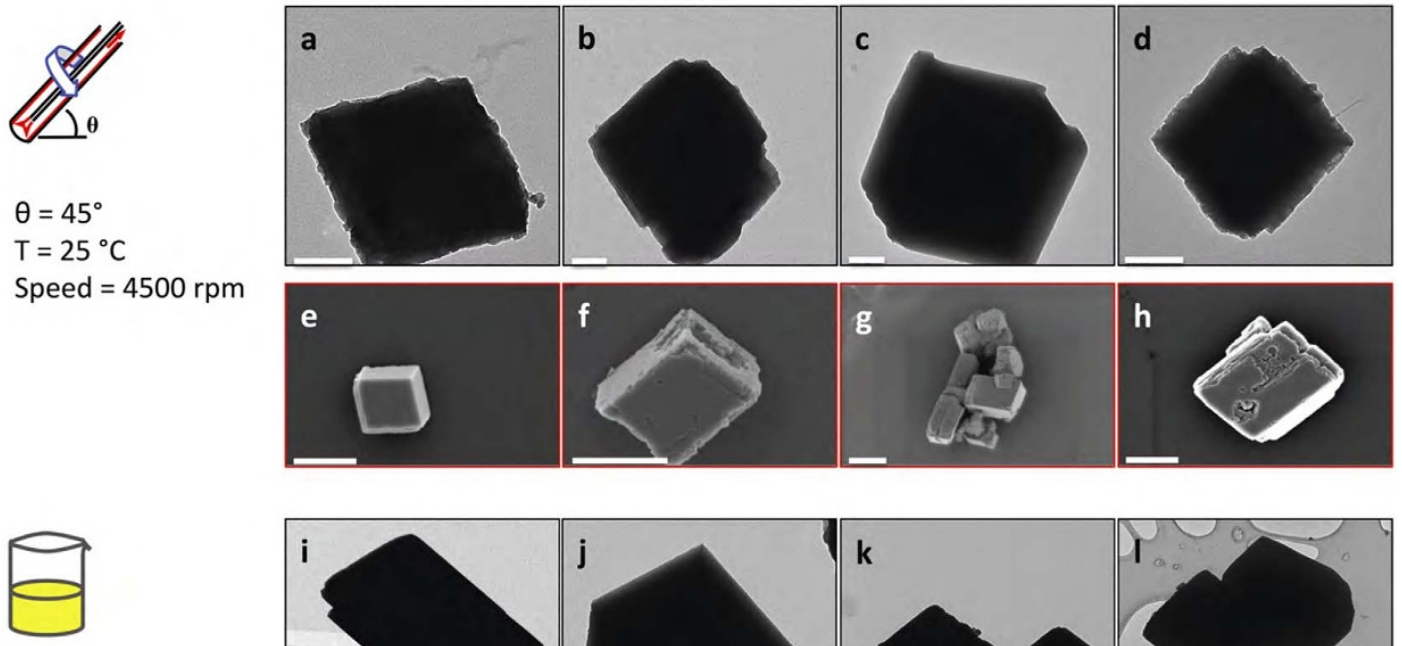

$\mathrm{T}=25^{\circ} \mathrm{C}$
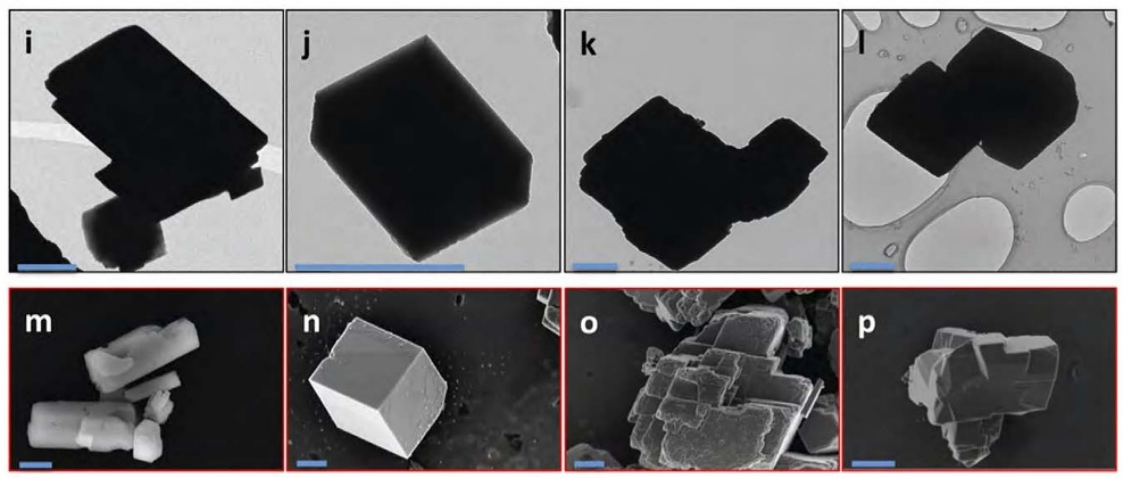

Figure $4 \mid$ Control of size, shape and morphology. TEM and SEM images of samples showing morphologies of calcite obtained at room temperature using the VFD at $4500 \mathrm{rpm}$ and $45^{\circ}$ tilt angle (a-h), and using batch processing (i-p). Scale bar for images (a) $-(\mathrm{d})$ is $200 \mathrm{~nm}$ and $1 \mu \mathrm{m}$ for the other images. 
Stock solutions of $\mathrm{NaHCO}_{3}$ and $\mathrm{CaCl}_{2}$ were made in Milli-Q water to give a final concentration of $1 \mathrm{M}$. The reactants were prepared in $1: 1,1: 2,2: 1,1: 3,3: 1,1: 10$ and $10: 1$ ratios of $\mathrm{HCO}_{3}{ }^{-}$to $\mathrm{Ca}^{2+}$. In the batch process, $15 \mathrm{~mL}^{2} \mathrm{CaCl}_{2}$ solution with the target concentration was added drop wise to $15 \mathrm{~mL}$ of $\mathrm{NaHCO}_{3}$ solution with the target concentration in a $50 \mathrm{~mL}$ conical flask. For the VFD under continuous flow, Fig. 1b, solutions of $\mathrm{NaHCO}_{3}$ and $\mathrm{CaCl}_{2}$ with the target concentrations were fed into the VFD at a flow rate of $1 \mathrm{~mL} / \mathrm{min}$ using a peristaltic pump with the VFD set to the desired angle and at the desired temperature. The $\mathrm{CaCO}_{3}$ obtained was filtered, washed with Milli-Q water and left to dry at room temperature.

Full methods and any associated references are available in the online version of the paper at www.nature.com/nature.

1. Millero, F. J. \& DiTrolio, B. R. Use of thermodynamics in examining the effects of ocean acidification. Elements 6, 299-303 (2010).

2. Cabemes, C., Cazenave, A. \& Le Provost, C. Sea level rise during past 40 years determined from satellite and in situ observations. Science 294, 840-845 (2001).

3. Baker, A. C., Glynn, P. W. \& Riegl, B. Climate change and coral reef bleaching: An ecological assessment of long-term impacts, recovery trends and future outlook. Est. Coast. Shelf Sci. 80, 435-471 (2008).

4. Addadi, L., Raz, S. \& Weiner, S. Taking advantage of disorder: amorphous calcium carbonate and its roles in biomineralization. Adv. Mater. 15, 959-970 (2003)

5. Weiss, J. M., Tuross, N., Addadi, L. \& Weiner, S. Mollusc larval shell formation: amorphous calcium carbonate is a precursor phase for aragonite. J. Exp. Zool. 293, 478-491 (2002).

6. Boulos, R. et al. Unzipping oyster shell. RSC Adv. 3, 3284-3290 (2013).

7. Orr, J. C. et al. Anthropogenic ocean acidification over the twenty-first century and its impact on calcifying organisms. Nature 437, 681-686 (2005).

8. Marubini, F., Ferrier-Pagès, C., Furla, P. \& Allemand, D. Coral calcification responds to seawater acidification: a working hypothesis towards a physiological mechanism. Coral Reefs 27, 491-499 (2008).

9. Steffen, W. et al. The Anthropocene: From global change to planetary stewardship. AMBIO 40, 739-761 (2011).

10. Wahid, M. H., Eroglu, E., Chen, X., Smith, S. M. \& Raston, C. L. Functional multilayer graphene-algae hybrid material formed using vortex fluidics. Green Chem. 15, 650-655 (2013)

11. Tong, C. L., Boulos, R. A., Yu, C., Iyer, K. S. \& Raston, C. L. Continuous flow tuning of ordered mesoporous silica under ambient conditions. RSC Adv. 3, 18767-18770 (2013)

12. Yasin, F. M. et al. Microfluidic size selective growth of palladium nano-particles on carbon nano-ionions. Chem. Commun. 48, 10102-10104 (2012).

13. Yasmin, L., Chen, X., Stubbs, K. A. \& Raston, C. L. Optimising a vortex fluidic device for controlling chemical reactivity and selectivity. Sci. Rep. 3, 2282 (2013).

14. de Villiers, J. P. R. Crystal structures of aragonite, strontianite, and witherite. Am. Mineral. 56, 758-767 (1971).

15. Markgraf, S. A. \& Reeder, R. J. High-temperature structure refinements of calcite and magnesite. Am. Mineral. 70, 590-600 (1985).

16. Wang, J. \& Becker, U. Structure and carbonate orientation of vaterite $\left(\mathrm{CaCO}_{3}\right)$ Am. Mineral. 94, 380-386 (2009).

17. de Leeuw, N. H. \& Parker, S. C. Surface structure and morphology of calcium carbonate polymorphs calcite, aragonite, and vaterite: an atomistic approach. J. Phys. Chem. B 102, 2914-2922 (1998).

18. McKinnon, J. J., Fabbiani, F. P. A. \& Spackman, M. A. Comparison of polymorphic molecular crystal structures through Hirshfeld surface analysis. Cryst. Growth Des. 7, 755-769 (2007).

19. Ogino, T., Suzuki, T. \& Sawada, K. The formation and transformation mechanism of calcium carbonate in water. Geochim. Cosmochim. Acta 51, 2757-2767 (1987).

20. Wray, J. L. \& Daniels, F. Precipitation of calcite and aragonite. J. Am. Chem. Soc. 79, 2031-2034 (1957).

21. Yoshioka, S. \& Kitano, Y. Transformation of aragonite to calcite through heating. Geochem. J. 19, 245-249 (1985).
22. Butler, M. F., Glaser, N., Weaver, A. C., Kirkland, M. \& Butler, M. H. Calcium Carbonate Crystallization in the Presence of Biopolymers. Cryst. Growth Des. 6 , 781-794 (2006)

23. Kirboga, S. \& Oner, M. Investigation of calcium carbonate precipitation in the presence of carboxymethyl inulin. CrystEngComm 15, 3678-3686 (2013).

24. Finnemore, A. et al. Biomimetic layer-by-layer assembly of artificial nacre. Nat. Commun. 3, 966 (2012).

25. Touaiti et al. Thermomechanical properties of $\mathrm{CaCO}_{3}$-latex pigment coatings: Impact of modified dispersing agents. Prog. Org. Coat. 76, 439-446 (2013).

26. Parakhonskiy, B. V., Haase, A. \& Renzo, A. Sub-micrometer vaterite containers: synthesis, substance loading, and release. Angew. Chem. Int. Ed. 51, 1195-1197 (2012).

27. Sand, K. K., Rodriguez-Blanco, J. D., Makovicky, E., Benning, L. G. \& Stipp, S. L. S. Crystallization of $\mathrm{CaCO}_{3}$ in water alcohol mixtures: Spherulitic growth, polymorph stabilization, and morphology change. Cryst. Growth Des. 12, 842-853 (2012).

28. Ries, J. B., Anderson, M. A. \& Hill, R. T. Seawater Mg/Ca controls polymorph mineralogy of microbial $\mathrm{CaCO}_{3}$ : A potential proxy for calcite-aragonite seas in Precambrian time. Geobiology 6, 106-119 (2008).

29. Davis, K. J., Dove, P. M. \& De Yoreo, J. The role of $\mathrm{Mg}^{2+}$ as an impurity in calcite growth. Science 290, 1134-1137 (2000).

30. Liu, F. et al. Biomimetic fabrication of pseudohexagonal aragonite tablets through a temperature-varying approach. Chem. Commun. 46, 4607-4609 (2010).

31. Adler, H. H. \& Kerr, P. F. Infrared study of aragonite and calcite. Am. Mineral. 47, 700-717 (1962)

32. Hetherington, P. PhD. Thesis, Process intensification: a study of calcium carbonate precipitation methods on a spinning disc reactor. University of Newcastle upon Tyne, (2006).

33. Northwood, D. O. \& Lewis, D. Transformation of vaterite to calcite during grinding. Am. Mineral. 53, 2089-2092 (1968).

34. Sekkal, W. \& Zaoui, A. Nanoscale analysis of the morphology and surface stability of calcium carbonate polymorphs. Sci. Rep. 3, 1587 (2013).

35. Wolf, G., Lerchner, J., Schmidt, H., Gamsjäger, H., Königsberger, E. \& Shmidt, P. Thermodynamics of $\mathrm{CaCO}_{3}$ phase transitions. J. Therm. Anal. 46, 353-359 (1996).

\section{Acknowledgments}

Support of this work by the Australian Research Council, The Government of South Australia, Pearl Technologies Pty Ltd, and Centre for Microscopy, Characterisation and Analysis at the University of Western Australia and Adelaide University is greatly acknowledged. F. Zhang is thankful for the support of China Scholarship Council for his study in Australia. The authors thank Bob Northeast for the 3D drawing of the VFD.

\section{Author contributions}

R.A.B. and F.Z. carried out fluid flow experiments, R.A.B., F.Z. and E.S.T. carried out characterisation, A.D.M. carried out the Hirshfeld surface analysis, R.A.B., D.S. and C.L.R. designed the experiments and wrote the paper, and C.L.R. designed the microfluidic platform and coordinated the research.

\section{Additional information}

Supplementary information accompanies this paper at http://www.nature.com/ scientificreports

Competing financial interests: The authors declare no competing financial interests. How to cite this article: Boulos, R.A. et al. Spinning up the polymorphs of calcium carbonate. Sci. Rep. 4, 3616; DOI:10.1038/srep03616 (2014). To view a copy of this license, visit http://creativecommons.org/licenses/by/3.0 